\title{
Significado de Comer e Percepção Corporal em Mulheres que Procuraram o Programa Multiprofissional Na Medida
}

\author{
Nayara Tiemi Naves ${ }^{1}$ \\ Alessandra Elisa Gromowski \\ Cristiane Vercesi \\ Silvia Nogueira Cordeiro \\ Universidade Estadual de Londrina, Londrina, PR, Brasil
}

\begin{abstract}
Resumo
A experiência subjetiva vivenciada socialmente e a imagem corporal formada na primeira infância são aspectos que contribuem para a percepção do próprio corpo. $O$ ato de comer vai além de seu significado histórico-cultural e passa por processos inconscientes. Objetivou-se conhecer o significado do comer e a percepção corporal de 27 mulheres que se interessaram em participar do programa multiprofissional $\mathrm{Na}$ Medida, residentes na região norte do Paraná, Brasil. Utilizou-se um questionário semiestruturado para o levantamento dos dados, que foram analisados a partir do conteúdo temático-categorial pelo referencial da psicanálise, considerando o contexto social. Os resultados demonstram que o comer, além de significar a preservação da espécie, está ligado a processos inconscientes que visam a busca por satisfação. As mulheres sentiam-se insatisfeitas com seu próprio corpo e verificou-se a tentativa de suprir a falta investindo no corpo, (re)significando-o e tentando criar uma imagem idealizada sob o olhar do Outro.
\end{abstract}

Palavras-chave: Imagem corporal, percepção, alimentação, psicanálise.

\section{The Meaning of Eating and Body Perception of Women that Sought the Na Medida Multidisciplinary Program}

\begin{abstract}
The subjective experience socially lived and the body image developed in the early childhood are aspects that contribute to the own body perception. The act of eating goes beyond its historical and cultural meaning and suffers unconscious processes. It is aimed at knowing the meaning of eating and the body perception of 27 women who were interested in participating of the multidisciplinary program $\mathrm{Na}$ Medida, residents in the north of Paraná State (Brazil). It was used a semi structured questionnaire for data collection, that were analyzed from the thematic-categorical context by the psychoanalysis reference, considering the social context. The results demonstrated that eating, besides meaning the species' preservation; is associated to the unconscious processes in search of satisfaction. The women have felt unsatisfied by their own body and it was checked the attempt to supply the fault by investing in the body, (re)framing it and trying to create an idealized image under the Other's gaze.
\end{abstract}

Keywords: Body image, perception, feeding, psichoanalysis.

Endereço para correspondência: Rua Pio XII, 865, Apto. 304, Centro, Londrina, PR, Brasil, 86020-381. E-mail: naytiemi@hotmail.com

Gostaríamos de agradecer a professora Dra. Clísia Mara Carreira, coordenadora do Projeto Na Medida, e aos residentes que participaram e colaboraram para a execução do projeto. 


\section{Significado del Comer y Percepción Corporal em las Mujeres que Buscaran el Programa Multiprofesional Na Medida}

\section{Resumen}

La experiencia subjetiva vivenciada socialmente y la imagen corporal formada en la primera infancia, son factores que contribuyen para la percepción del propio cuerpo. El acto de comer va más allá de su significado histórico-cultural, y transcurre por procesos inconscientes. El objetivo fue conocer el significado del comer y la percepción corporal de 27 mujeres que tuvieron interés de participar de un programa multiprofesional Na Medida y que residían en la región norte de la provincia de Paraná (Brasil). Se utilizó un cuestionario semiestructurado para el levantamiento de los datos. Esto fueron analizados a partir de un contenido temático-categorial por referencia de la psicoanálisis, considerando el contexto social. Los resultados demuestran que el comer además de significar la preservación de la especie, esta ligado a procesos inconscientes para una busca de satisfacción. Las mujeres se sentían insatisfechas con su propio cuerpo y se verificó una tentativa de suprimir esa falta, realizando una inversión en su cuerpo, (re)significandoló y tentando crear una imagen idealizada sobre el mirar del Outro.

Palabras clave: Imagen corporal, percepción, alimentación, psicoanalisis.

"Para além do corpo biológico e da fome fisiológica, existe um corpo que demanda, mas não se sacia"

(Seixas, 2009).

\section{Percepção da Imagem Corporal e do Corpo Ideal}

A imagem corporal pode ser considerada um conjunto de imagens ou como uma pessoa representa para si seu próprio corpo e é um conceito de construção múltipla. As vivências perceptivas e subjetivas sociais colaboram na construção da imagem corporal (Sousa, 2007). Em outras palavras, pode ser definida por como a pessoa se vê, sente e experimenta seu corpo dentro de sua cultura e sociedade, ligado a fatores emocionais, fisiológicos e experiências pessoais, crenças, comportamentos, abarcando também o relacionamento com o outro (Leal, Catrib, Amorim, \& Montagner, 2010; Secchi, Camargo, \& Bertoldo, 2009; Stenzel, 2006).

A aparência que o corpo mantémé de grande importância na sociedade contemporânea; contudo, o aspecto subjetivo apresenta uma força psicossocial de maior influência (Stenzel, 2006), ou seja, é esperado dos indivíduos que se aparentem de certa forma e a percepção sobre a própria imagem que gera maior preocupação.
Dessa forma, pode-se falar sobre a percepção da imagem corporal, tendo em vista que a autopercepção abrange de autoimagem, pois se constitui a partir das impressões sobre o próprio corpo e o quanto a pessoa preocupa-se consigo mesma em relação às preocupações com o mundo externo (Sousa, 2007).

O corpo ideal buscado pelas mulheres é o longilíneo e magro, abaixo do índice de massa corporal considerado normal pela Organização Mundial de Saúde (Kakeshita \& Almeida, 2006; Martins et al., 2012; Secchi et al., 2009), dado que influencia no modo e na qualidade de vida dessas mulheres, pois acabam se sujeitando a restrições alimentares, exercícios físicos, medicamentos, entre outros. Tais procedimentos podem acarretar sofrimento psíquico e muitas vezes danos ao próprio corpo, como a insatisfação com a imagem corporal ou até mesmo distúrbios da imagem corporal (Kakeshita \& Almeida, 2006).

O reforço dado pela mídia em mostrar corpos atraentes é de grande importância na construção da imagem corporal. A mídia é difusora de valores, informações e comportamentos que são reforçados nas relações cotidianas com os colegas e família, e geralmente ressalta as características do corpo de sucesso, gerando, por consequência, expectativas e desejo nos consumidores (Cash, 
2005). A indústria corporal, através dos meios de comunicação, encarrega-se de criar desejos e reforçar imagens, surgindo assim padronizações. Pessoas que se veem fora desse padrão medidas sentem-se cobradas e insatisfeitas.

Pesquisas sobre insatisfação corporal entre mulheres e adolescentes do gênero feminino apontam que a exposição aos conteúdos midiáticos de padrões de beleza, a comparação entre seu próprio corpo e o exposto, além da frustração em obter o corpo ideal, acarreta baixa autoestima e insatisfação com a imagem corporal (Alves, Pinto, Alves, Mota, \& Leirós, 2009; Martins, Pelegrini, Matheus, \& Petroski, 2010; Posavac, Posavac, \& Weigel, 2010).

Pode-se associar, hoje, o corpo à ideia de consumo. Em muitos momentos, este é objeto de valorização exagerada de bens e serviços destinados à "manutenção deste corpo". Como afirma Fernandes (2003), "O corpo está em alta! Alta cotação, alta produção, alto investimento... Alta frustração" (p. 13).

A inadequação corporal gera um "ódio à gordura" e leva as pessoas a adotarem práticas de agressão a si mesmas, como o controle excessivo da alimentação para adequarem-se aos padrões vigentes na sociedade (Freire \& Andrada, 2012; Sibilia, 2006). Sibilia (2006) dá exemplos de práticas, como o jejum prolongado, alimentação de luz solar e alimentação restrita a sementes e grãos, para ilustrar a ideia de purificação orgânica, o corpo que deve ser limpo e desintoxicado pela estratégia da fome, pois a carne é impura.

Para atingir a beleza, acredita-se que se deva comer pouco, apesar da recomendação da medicina insistir no equilíbrio. A noção de "comer como um passarinho" carrega uma herança histórica advinda da Idade Média até os dias de hoje (Asfora, 2012). Os alimentos são associados com saúde em todas as culturas pela questão da sobrevivência humana e do discurso da medicina sobre tipos de dieta (Carneiro, 2005).

A imagem da pessoa gorda carrega um estigma social que as pessoas buscam evitar, qual seja, o de carregar o estereótipo do amável e simpático, ao mesmo tempo, o do julgamento e asco alheio pela sua gordura. $\mathrm{O}$ gordo é visto como aquele que não consegue administrar o próprio o corpo e seus limites, como uma pessoa que não se esforça para conter suas medidas (Novaes \& Vilhena, 2003).

Assim, a alimentação ou o ato de comer, além de sua função de prover energia e valores nutritivos ao corpo, carrega fortes sentidos dentro de um contexto histórico, cultural e social, acompanha ritos de passagem, relações sociais, construção de vínculos e produz identidades tanto individuais quanto coletivas (Carvalho, Luz, \& Prado, 2011).

\section{O Comer ao Longo da História}

A história da alimentação remete a uma sociedade que se expressa através dos hábitos alimentares e seus sentidos são modificados continuamente.

Em uma breve retrospectiva histórica, Flandrin e Montanari (1998) concluíram que, na Grécia, o principal aspecto da alimentação era a importância dada ao banquete por sua estreita ligação com o processo de reprodução do corpo social, pois definia a condição de humano e diferenciava os gregos das demais sociedades. Assim como os gregos, os antigos egípcios associavam a preservação da saúde à quantidade de comida ingerida.

Seguindo a evolução dos tempos, Mazzini (2000) acrescenta que na Idade Média essas exigências passam a definir as classes sociais a que cada pessoa pertence, pois a sociedade cristã ajudou na proliferação das orientações alimentares e do seu impacto social, quando associou a comida ao pecado da gula.

Flandrin e Montanari (1998) afirmam que foi nos séculos XVII e XVIII que as elites permitiram um afrouxamento nas regras alimentares, favorecendo a entrada de novos alimentos no cardápio e também uma busca pela satisfação do gosto em detrimento da boa saúde, associando ao gosto do alimento um valor estranho, ou seja, um sentido figurado para discernir o comestível do não comestível.

Na passagem do século XVIII ao século XIX, houve o crescimento demográfico, o desenvolvimento das cidades e a industrialização, além da ampliação dos mercados e a conquista de novas terras. Tais fatos fizeram surgir na 
figura da burguesia ascendente a gordura como símbolo de riqueza e distinção social (Flandrin $\&$ Montanari, 1998).

Diferentemente do que é visto atualmente, pois os hábitos alimentares do brasileiro e o significado do alimento foram modificados nas últimas décadas, a saber, consumo de alimentos rápidos e práticos vem aumentando, além de refeições solitárias, industrializadas e com menor valor nutricional, que favorecem o comer demais, a obesidade e suas co-morbidades (Bleil, 1998).

A obesidade, considerada doença, cresce em uma epidemia mundial, resultado da associação de hábitos alimentares inadequados do ponto de vista nutricional e do sedentarismo, e aparece em todas as idades e classes sociais (Ministério da Saúde, 2006).

Apesar disso, a fome não deixou de ser um problema social, pois o novo modo de produção cria desigualdades.

O processo de globalização da sociedade capitalista contemporânea homogeneizou os modos de vida da população de maneira geral e modificou os hábitos alimentares. O calendário não se regula mais pelo tempo da colheita e festividades religiosas, mas por dias úteis de trabalho, finais de semana e feriados. Da mesma forma que os alimentos não se restringem mais a determinada região ou época, são comercializados em supermercados que integram relações, trocas, pessoas e atividades (Hernández, 2005).

A mídia e a propaganda, ao enfocar a importância de alimentos saudáveis, criam um novo mercado de consumo, como a dos alimentos diet e light, que prometem equilíbrio nutricional, sabor e praticidade, mesmo o alimento sendo industrializado (Marins, Araújo, \& Jacob, 2011). Ao mesmo tempo, mas ainda dentro do processo mercadológico, são resgatadas as tradições da cozinha e da culinária pelos gastrônomos e a identidade local e cultural valorizada por alguns setores do mercado (Hernández, 2005).

\section{Pulsão e Imagem Corporal: O Comer Além da Fome}

Varela (2006) questiona o que faz o ser humano continuar comendo quando sua necessida- de fisiológica, a fome, já está satisfeita. Sugere, então, que a comida seria um objeto pulsional vinculado à história, desejo e fantasias da pessoa. Isto é, o comer é pulsional, uma forma de expressão que não ocorre por meio da linguagem, mas no encher do corpo.

$\mathrm{Na}$ medicina, o vício é associado ao organismo que se desregula, se altera por determinada patologia. A perspectivada psicanálise propõe o vício como a compulsão pela demanda do objeto, caracterizando o comer em excesso como um sintoma, como ações mediadas pelo inconsciente (Campos, Ferreira, Cunha, \& Braun, 2012; Rocha, Vilhena, \& Vilhena Novaes, 2009; Seixas, 2009).

A pulsão, para Freud (1905/2006b), seria o limite entre o físico e o psíquico. Ele distinguiu dois tipos de pulsões humanas: autoconservação e sexual. A primeira tem objetivo específico de sobrevivência e não pode ser adiado por muito tempo. O segundo contém a pulsão de autoconservação mais uma quantidade de libido que torna a relação com o objeto erotizada. O corpo é tanto fonte constante dessa pulsão quanto sua finalidade. O objetivo da pulsão é a satisfação, mesmo que parcial, e ela utiliza-se de objetos, por exemplo, o alimento, como meio para atingir este objetivo.

Quando o ser humano nasce, encontra-se em um estado de desamparo, permeado por essas pulsões e excitações. Tais pulsões são satisfeitas no próprio corpo, em zonas erógenas. Primeiramente na boca, associado ao sugar o leite e suprir a fome: em seguida utilizando-se partes do corpo, como o dedo, a mão, o pé, caracterizando o autoerotismo. Os cuidados maternos para atender as necessidades do bebê, juntamente com as experiências sensoriais e as reações do círculo humano, fornecem o primeiro espelho à criança, que vai constituindo seu eu a partir do que é refletido. A figura materna adquire sua importância como o Outro que investe neste ser com sua presença e seu olhar (Anzieu, 1989; Freud, 1905/2006b).

Assim o bebê, num primeiro momento, vivencia seu corpo como partes cindidas. $\mathrm{O}$ primeiro local de satisfação é a boca, pois a fome é a primeira necessidade a ser suprida pela mãe e 
o sugar apoia-se em uma função somática, para depois ser direcionada a outros objetos como o próprio dedo (Freud, 1905/2006b). Segundo Freitas, Moreira, Freitas e Lamounier (2006) a mãe deve saber diferenciar as necessidades deste filho (fome, carinho, troca), pois ao se dar alimento todas as vezes que o filho chora, pode estar ensinando uma relação anormal com a comida.

As sensações de conforto ou desconforto são sentidas em regiões corporais, sem ligação entre elas. Para que essas sensações se integrem e o corpo possa ser vivenciado como um, é necessária a constituição de uma imagem corporal, que se organiza através do olhar do Outro, a mãe (Cabas, 1982; Lacan, 1949/1998; Winnicott, 1967).

Portanto, é a partir das experiências que o bebê estabelece com sua mãe, de ser acariciado ou contido, de ser reconhecido por ela como sujeito e receber um lugar como tal, ajudam o bebê a fazer a diferenciação entre eu e não-eu e a constituir sua subjetividade (Jerusalinsky, 2006).

Os olhos têm como função apreender o mundo externo, mas não apenas isso. Eles servem também para perceber os encantos dos objetos que são escolhidos como objetos de amor. Isso ocorre em função de as pulsões se utilizarem dos mesmos órgãos e sistemas corporais que servem à sobrevivência, de modo que o ato de ver se compõe de processos tanto conscientes quanto inconscientes (Freud, 1910/1996a).

A função do olhar, dessa forma, é uma pulsão que Freud (1915/1996b) denominou de pulsão escópica e que envolve tanto olhar quanto ser olhado. Primeiro há a visão de objetos externos e, em seguida, a percepção da visão do Outro sobre si mesmo. A satisfação decorrente desse ato está relacionada à libido, como uma forma de troca, entre eu e o Outro.

Aprofundando a teoria de Freud, Lacan (1949/1998) discorre sobre a imagem corporal e a formação deste contorno do corpo. Sua teoria sobre o estádio do espelho trata de um marco significativo no desenvolvimento infantil. Segundo o autor, o bebê, após os seis meses de idade, diferentemente do macaco ou do chimpanzé, ao se olhar no espelho, se reconhece e passa a executar diferentes gestos, explorando sua pró- pria imagem. O espelho integra o corpo infantil, até então percebido pela própria criança de forma fragmentada. É este processo de integração da imagem no espelho, apoiado por um adulto, que possibilita o bebê se identificar com a própria imagem.

Ao ver sua própria imagem, fantasia-se completo. O bebê cria uma tensão ao formar esta imagem unificada e ao mesmo tempo possuir uma impotência motora. Desse modo, formula um eu que irá sempre precisar de reconhecimento para que sua imagem se fixe, pois a certeza de coincidir com a própria imagem vem de fora (Lacan, 1949/1998).

A passagem pelo estádio do espelho, de modo simbólico, é uma das condições à compreensão da existência tanto de si quanto do Outro. O espelho, na teoria lacanaina, tem função de integração corporal e, portanto, do eu.

Vale ressaltar que existem outras abordagens para este mesmo tema dentro da psicanálise. Entretanto nesse artigo optou-se por trabalhar a partir desses conceitos.

Percebe-se, então, a diferença entre o corpo estudado pela medicina, anatomofisiológico ou biológico, e o corpo da psicanálise, fonte e finalidade das pulsões e em constante busca por satisfação. Varela (2006) aponta que, se o instinto supre a necessidade do corpo biológico, a pulsão estabelece o corpo da psicanálise. Desse modo, o que o instinto não consegue satisfazer diz respeito ao corpo pulsional.

\section{Busca pela Estética e pela Saúde}

A satisfação dos desejos pulsionais se deu de forma completa supostamente somente quando o bebê ainda não se diferenciava de sua mãe e sentia-se onipotente, e, a partir de sua diferenciação do mundo externo, o sujeito estará em busca constante para reviver tal satisfação. Contudo, ela se dará somente de forma parcial (Freud, 1905/2006b).

Além disso, segundo Freud (1930/2006a), existem três fontes de sofrimento que são sentidas como ameaças e geram constante mal-estar. O próprio corpo é uma delas, pois ele está condenado à decadência, à morte, sem poder escapar da ansiedade que isso causa. As outras duas 
correspondem ao mundo externo e sua força destrutiva e aos relacionamentos com os outros, pois as próprias regras humanas não significam benefício e segurança. Assim, conclui que o ser humano está sempre em busca da felicidade, seja de forma ativa ou tentando evitar o desprazer e, para isso, recorre a métodos como a solidão ou o amor, a beleza e a arte. Segundo Freud (1930/2006a), a beleza teria efeitos de compensação ao sofrimento; assim, a busca pela estética do belo no corpo não foge disso.

Os avanços tecnológicos e da ciência foram desenvolvidos pelo ser humano a fim de tentar preencher o sentimento de vazio e aliviar o sofrimento. A possibilidade do consumo como felicidade plena é apresentada pelas novas leis do mercado capitalista (Carneiro \& Pinheiro, 2009). Tendo em vista que, na contemporaneidade, o corpo belo é o corpo magro e/ou forte, esculpido (Goldenberg, 2005), o consumo de novos alimentos apresentados como saudáveis, de receitas em livros de dietas famosos e procedimentos invasivos como cirurgias de modificação corporal são alguns exemplos das ofertas para a procura pela beleza do corpo.

Pode-se notar também a popularização de academias, centros de saúde e clínicas de nutrição que prometem o alcance da forma corporal perfeita de forma saudável. Não obstante, tendo em vista a melhora na qualidade de vida da população e a redução dos casos de obesidade, órgãos governamentais criaram ações e estratégias para a promoção da alimentação saudável e exercícios físicos, desenvolvidas pela articulação entre governo, setores produtivos, sociedade civil e comércio (Coutinho, Gentil, $\&$ Toural, 2008).

Outra forma criada para suprir a demanda pelo corpo saudável são os programas de emagrecimento, que se tornaram populares pela mídia televisiva, exaltando a melhora tanto na forma física e na saúde, quanto na autoestima e imagem corporal da pessoa participante. Com o advento das equipes multidisciplinares na área de Saúde Coletiva, tais programas tornaram-se passíveis de serem realizadas com a comunidade em geral, tendo em vista que o acompanhamen- to nutricional, físico e psicológico, mesmo em curto prazo, tem resultados na composição corporal, como a redução do percentual de gordura, nos hábitos alimentares e estilo de vida (França, Biaginni, Mudesto, \& Alves, 2012; Saueressig \& Berleze, 2010).

Neste sentido, este estudo teve como objetivo conhecer o significado de comer e a percepção corporal das mulheres que procuraram o programa multiprofissional $\mathrm{Na}$ Medida.

\section{Método}

Foi realizado um estudo exploratório com o objetivo de descrever a percepção da imagem corporal e o significado do comer para as mulheres que se interessaram por participar do programa multiprofissional $\mathrm{Na}$ Medida. Este projeto foi submetido e aprovado pelo Comitê de Ética em Pesquisa com Seres Humanos da Universidade Estadual de Londrina, $\mathrm{n}^{\circ}$ de aprovação 239/2013.

O programa multiprofissional envolveu as seguintes áreas: psicologia, nutrição, educação física, enfermagem e farmácia com finalidade de atender mulheres com doenças cardiovasculares e metabólicas, em idade reprodutiva, para que tivessem mudanças significativas na qualidade de vida, as quais seriam advindas da reeducação alimentar, prática de exercícios físicos, saúde mental e aspectos gerais da saúde da mulher.

Participaram deste estudo 27 mulheres que residiam na região norte do estado do Paraná e eram atendidas pela Unidade Básica de Saúde de seu bairro. A faixa etária foi de 32 a 68 anos, isto é, a média de idade das mulheres foi de 50 anos. Foram coletados dados sobre queixa de saúde, uso de medicamentos, pressão arterial e índice de massa corporal (IMC). A participação foi voluntária e todas assinaram o Termo de Consentimento Livre e Esclarecido.

A amostra foi proposital e por saturação, ou seja, as mulheres foram escolhidas de acordo com características pessoais que trariam informações sobre o tema do presente estudo e a amostra foi fechada quando as respostas tornaram-se repetitivas (Turato, 2003). 
Foi aplicado pela psicóloga um questionário com perguntas semiestruturadas, a saber: "em uma palavra, o que comer significa para você" e "como você se sente em relação ao seu corpo?", a fim de conhecer os significados de comer e a percepção corporal.

A análise dos dados foi feita a partir do conteúdo temático-categorial. Para tanto, utilizou-se das etapas propostas por Turato (2003) para análise de conteúdo: Pré-análise (leitura flutuante), categorização dos tópicos emergentes segundo critérios de relevância e de repetição, validação externa (supervisão com orientador, discussão com grupo de pesquisa e debate dos resultados em eventos) e apresentação dos resultados (descritivo, com ilustrações das respostas). E foram incluídas etapas da análise de conteúdo temático-categorial que complementam as anteriores: definição de hipóteses provisórias, determinação de unidades de registro, definição dos temas por meio das unidades de registro, quantificação dos temas e análise categorial do texto (Oliveira, 2008).

Para a discussão dos resultados, utilizou-se o referencial da psicanálise, além de ter sido considerado o contexto sócio-histórico contemporâneo.

\section{Resultados e Discussão}

\section{Significado de Comer}

Neste tema Significado de comer, foram analisadas as categorias: sobrevivência; sentimentos de prazer; sentimentos de desprazer; gula e saúde.

Na Tabela 1 é demonstrada a porcentagem de respostas para cada categoria.

Tabela 1

Número de Respostas e Porcentagem das Respostas em Cada Categoria

\begin{tabular}{ccc}
\hline Categorias & $\mathrm{n}^{\text {o de respostas }}$ & $\%$ \\
\hline Sentimentos de prazer & 10 & 37 \\
Sobrevivência & 8 & 30 \\
Sentimentos de desprazer & 6 & 22 \\
Saúde & 2 & 7 \\
Gula & 1 & 100 \\
\hline Total & 27 & 4 \\
\hline
\end{tabular}

A sobrevivência, ilustrada pelas falas "saciar a fome", "alimentar o físico", "sustentar", remete ao instinto de fome e preservação da vida e espécie presente em todos os animais. A associação com seu significado denotativo sugere que as mulheres limitaram-se à realidade concreta, ou seja, ao dar o significado literal para o ato de comer, não houve um contato ou elaboração da resposta com a própria história, cultura ou emoções.

A categoria saúde encontra-se na mesma perspectiva, pois, como já dito anteriormente, a alimentação é relacionada à questão de sobrevivência em diferentes culturas (Carneiro, 2005).
Contudo, esta ideia também pode ter sido influenciada pela proposta de uma vida saudável para prevenção de doenças, pois, a alimentação saudável e a atividade física são consideradas principais meios para a promoção de saúde (Ministério da Saúde, 2006). Ou seja, as falas que dão significado ao comer como "saúde" contém um aspecto positivo, levando em consideração a mudança nos costumes alimentares dos brasileiros que favorecem o comer excessivo e a obesidade (Bleil, 1998). Ideia que o mercado de consumo apropriou-se, ofertando alimentos diet, light ou que sugerem cuidado com o próprio corpo (Marins et al., 2011). 
As demais categorias apontam para outra direção. Houve a relação do comer com sentimentos de prazer, por exemplo, através das falas "comer é tudo de bom", "satisfação", "prazer", "suprir a tristeza", "alivio", e também houve relação do comer com sentimentos de desprazer nas falas "horrivel", "problema", "controle". Varela (2006) afirma que a fome pode ser confundida com os sentimentos, caracterizando a fome pulsional, quando se continua a comer mesmo quando o corpo está saciado.

Como referido acima, antes de constituir um eu, o bebê é permeado por pulsões constantes que são satisfeitas em locais específicos, nas zonas erógenas. A primeira satisfação vivenciada pelo bebê se dá por meio do sugar o leite, aplacando a fome e proporcionando prazer, posteriormente, o prazer é direcionado a outros objetos, como o próprio dedo (Freud, 1905/2006b). Ao identificar as diferentes solicitações do bebê, por exemplo, o choro de fome, do choro da dor, e ofertando o alimento no momento adequado, constrói uma relação que irá influenciar as demais relações deste indivíduo e também aquelas relacionadas à alimentação e satisfação oral (Freitas et al., 2006).

Por fim, as mulheres deram o significado de "gula" ao comer. A gula é caracterizada pela religião como o comer em excesso, consistindo em um pecado. Os pecados têm como aspecto principal serem algo que excede ou que falta na relação do sujeito com o Outro. Assim, pode-se afirmar que a gula e as emoções que a acompanham não são mediadas pela consciência, mas sim reguladas pelo inconsciente; em outras palavras, a gula nomeia o gozo (Campos et al., 2012).

Desse modo, observa-se que, mesmo quando não referiam ao comer ligado diretamente aos sentimentos de prazer e de desprazer, ele foi relacionado a processos inconscientes em constante busca pela satisfação plena, gerando constante mal-estar.

\section{Percepção da Imagem Corporal}

Neste tema foi analisada a categoria: insatisfação com o próprio corpo. As falas eram de que as mulheres percebiam seu corpo como "gordo", "enorme", "me sinto feia", "não me vejo no espelho", "tô bem, pesava 70 quilos, mas agora tô com 66", "indisposição, impotência, tristeza". Todas as mulheres tiveram falas sobre insatisfação com o próprio corpo, ou seja, nenhuma mulher referiu estar bem consigo mesma ou não querer mudanças.

Tais falas corroboram com pesquisas que apontam que as mulheres e adolescentes apresentam insatisfação com a imagem corporal, além de baixa autoestima, pois comparam seus corpos aos expostos pelos conteúdos da mídia, mesmo que estes tenham suas imagens manipuladas para aparecerem sem imperfeições (Alves et al., 2009; Martins et al., 2010; Posavac et al., 2010).

O corpo está inserido na cultura e é marcado por ela. Na cultura contemporânea narcísica, a característica principal a que aqui se dá ênfase é a lipofobia, isto é, o horror a gordura (Freire $\&$ Andrada, 2012). O gordo é visto como aquele que não consegue ter controle de seu corpo e também não se esforça para isso (Novaes \& Vi1hena, 2003). Considerando que a sociedade capitalista instaura o indivíduo e a ascensão e valoração pessoal como mérito e esforço individual, o gordo seria incapaz de manter a boa aparência e é o único responsável por sua condição.

As mulheres relataram não se sentirem somente "gordas", mas também "feias", "com baixa autoestima" e "não me olho no espelho". Percebe-se, então, que o desconforto consigo mesma vai além do peso. Ao mudar o corpo por meio de intervenções estéticas se estaria mudando a vida e disso decorrem gratificações sociais advindas do processo. O que é apresentado como norma para a mulher é a constante afirmação de que ela pode ser bela, se assim quiser. Ou seja, não é a imposição ou a obrigação que exercem maior influência em relação à busca pela beleza, mas a possibilidade de qualquer mulher poder ser bela, sendo também responsável por isso (Novaes \& Vilhena, 2003).

Como referido na introdução, a imagem corporal é formada na primeira infância no investimento pulsional do Outro no corpo, que é sentido como fragmentado, e a acomodação dessa imagem se dará durante a vida toda, isto é, 
o sujeito irá buscar uma imagem para confirmar sua forma (Rocha et al., 2009).

Ao investir no próprio corpo, a mulher tenta suprir a sua falta, (re)significando este corpo e tentando criar uma imagem idealizada sob o olhar do Outro. Atrair o olhar do Outro traz a sensação de garantir a identidade feminina para a mulher, identidade que é formada por meio do embelezamento, uso de acessórios e maquiagem. Além disso, o buscar deste ideal de forma em que o sujeito se torna aprisionado sugere que existe um obstáculo na aceitação da finitude (Silva \& Rey, 2011).

Desse modo, a dependência do olhar desejante do Outro continua a existir, mesmo que este Outro seja a mídia (Lima, Batista, \& Lara, 2013). Se a mídia reforça o corpo belo e perfeito, a mulher vem a se reconhece a partir deste desejo social (Zorzan \& Chagas, 2011).

A percepção do próprio corpo, da imagem corporal e a relação que se estabelece com a comida são construídas durante toda a vida, até mesmo antes do nascimento, quando os pais investem desejo e expectativas naquele ser que está sendo gerado. Assim, é importante considerar que cada ser humano é único e estabelece relações únicas com o mundo e consigo mesmo; portanto, as mulheres que participaram deste estudo podem não representar toda a população, mas refletem um aspecto marcante e atual que diz respeito ao sofrimento humano.

O sintoma corporal, como a obesidade, pode ser entendido como um processo em que as questões subjetivas seguem um caminho adverso ao caminho que levaria ao processo de representação simbólica. $\mathrm{O}$ excesso de peso traduz no corpo questões do sofrimento psíquico que não pode ser simbolizado (Varela, 2006).

\section{Considerações Finais}

O presente estudo teve como objetivo conhecer o significado de comer e a percepção corporal das mulheres que procuraram o programa multiprofissional Na Medida. Nesse sentido, as mulheres entrevistadas deram para o ato de comer o significado de sobrevivência e saúde, que remete ao instinto de fome e preservação de espécie. Contudo, significados relacionados a sentimentos de prazer e desprazer, bem como ligados a processos inconscientes demonstram que o comer também vai além da fome, sendo muitas vezes um meio de aplacar momentaneamente a angústia. Este manejo da angústia é forma precária do funcionamento psíquico, que busca pela satisfação plena, supostamente alcançada em momento da vida, quando o eu ainda não havia sido formado, ou seja, quando bebê não se diferenciava de sua mãe e vivia em estado de onipotência e satisfação autoerótica.

A dinâmica de comer em excesso fornece ao sujeito recursos simbólicos para lidar com a frustração resultante da impossibilidade de preenchimento e satisfação plena da demanda. Assim o corpo obeso e a própria fome parecem manifestar a pulsão, no ponto em que não há a captura pela linguagem, evidenciando a estreita relação entre o corpo somático e o corpo pulsional da psicanálise (Seixas, 2009).

A mesma busca por satisfação aparece na percepção do próprio corpo. Ao se dizerem "gordas", "enormes" e "feias", demonstram insatisfação perante o ideal de corpo perfeito construído socialmente na cultura capitalista contemporânea. Embelezar-se para atrair o olhar do Outro, a fim de suprir a falta, é uma característica da cultura narcísica estimulada pelo consumo.

Apesar de os resultados não permitirem generalização, tais análises demonstram a importância do atendimento multiprofissional com a presença do profissional de psicologia nos programas de melhora da qualidade de vida, pois tratam diretamente da imagem corporal dos participantes, ligados a sentimentos e a processos inconscientes que não podem deixar de ser trabalhados. Também permitem uma melhor compreensão dos temas aqui estudados e servem de base para novos estudos.

\section{Referências}

Alves, D., Pinto, M., Alves, S., Mota, A., \& Leirós, V. (2009). Cultura e imagem corporal. Motricidade, 5(1), 1-20. Recuperado em http://www. scielo.oces.mctes.pt/scielo.php?pid=S1646$-107 X 2009000100002 \&$ script $=$ sci_arttext 
Anzieu, D. (1989). O Eu-pele. São Paulo, SP: Casa do Psicólogo.

Asfora, W. (2012). Comer como um passarinho, cozinhar como uma feiticeira: A herança edênica na construção da relação entre gênero e comida. Cadernos Pagu, 39, 431-445. doi:10.1590/ S0104-83332012000200015

Bleil, S. I. O. (1998). Padrão alimentar ocidental: Considerações sobre a mudança de hábitos no Brasil. Cadernos de Debate, 6, 1-25. Recuperado em http://pessoal.utfpr.edu.br/suseli/ arquivos/O_Padrao_Alimentar_Ocidental_consideracoes_sobre_a_mudanca_de_habitos_no_ Brasil.pdf

Cabas, A. G. (1982). Curso e discurso da obra de Jacques Lacan. São Paulo, SP: Moraes.

Campos, S., Ferreira, R. A., Cunha, C. F., \& Braun, L. (2012). Comida: Semblante do objeto A. Psicologia em Revista (Belo Horizonte), 18(1), 28 40. doi:10.5752/P.1678-9563.2012V18N1P28

Carneiro, H. S. (2005). Comida e sociedade: Significados sociais na história da alimentação. História: Questões \& Debates, 42, 71-80. Recuperado em http://ojs.c3sl.ufpr.br/ojs2/index.php/ historia/article/view/4640/3800

Carneiro, H. F., \& Pinheiro, R. L. (2009). As falácias da eliminação do sofrimento e seus efeitos subjetivos. Psico, 40(2), 245-252. Recuperado em http://revistaseletronicas.pucrs.br/ojs/index.php/ revistapsico/article/view/4210/4538

Carvalho, M. C. V. S., Luz, M. T., \& Prado, S. D. (2011). Comer, alimentar e nutrir: Categorias analíticas instrumentais no campo da pesquisa científica. Ciência \& Saúde Coletiva, 16(1), 155163. doi:10.1590/S1413-81232011000100019

Cash, T. F. (2005). The influence of sociocultural factors on body image: Searching for constructs. Clinical Psychology Science and Practice, 12(4), 438-442. doi:10.1093/clipsy.bpi055

Coutinho, J. G., Gentil, P. C., \& Toural, N. A. (2008). A desnutrição e obesidade no Brasil: O enfrentamento com base na agenda única da nutrição. $\mathrm{Ca}$ derno de Saúde Pública, 24(Supl. 2), S332-S340. doi:10.1590/S0102-311X2008001400018

Fernandes, M. H. (2003). Corpo. São Paulo, SP: Casa do Psicólogo.

Flandrin, J. L., \& Montanari, M. (1998). História da alimentação. São Paulo, SP: Estação Liberdade.
França, C. L., Biaginni, M, Mudesto, A. P. L., \& Alves, E. D. (2012). Contribuições da psicologia e da nutrição para a mudança do comportamento alimentar. Estudos de Psicologia (Natal), 17(2), 337-345. doi:10.1590/S1413$-294 X 2012000200019$

Freire, D. S., \& Andrada, B. C. C. (2012). A violência do/no corpo excessivo dos transtornos alimentares. Cadernos de Psicanálise, 34(26), 27-36. Recuperado em http://pepsic.bvsalud. org/scielo.php?script=sci_arttext\&pid=S0103$-42512012000100003 \& \operatorname{lng}=$ pt\&nrm=iso\&tlng $=\mathrm{pt}$

Freitas, V. G., Moreira, J. O., Freitas, A. E., \& Lamounier, J. A. (2006). Uma reflexão psicológica sobre a obesidade na infância e adolescência: Da falta de amor à fome de amor. Revista Médica (Minas Gerais), 16(4, Supl. 4), S225-228. Recuperado em http://www.smp. org.br/2008/vector/materia/arquivos/arquivos/ arquivo_bsdXsm.pdf

Freud, S. (1996a). A concepção psicanalítica da perturbação psicogênica da visão. In S. Freud (Ed.), Edição standard brasileira das obras psicológicas completas de Sigmund Freud: Vol. XI. Rio de Janeiro, RJ: Imago. (Original publicado em 1910)

Freud, S. (1996b). Os instintos e suas vicissitudes. In S. Freud (Ed.), Edição standard brasileira das obras psicológicas completas de Sigmund Freud: Vol. XIV. Rio de Janeiro, RJ: Imago. (Original publicado em 1915)

Freud, S. (2006a). O mal-estar na civilização. In S. Freud (Ed.), Edição standard brasileira das obras psicológicas completas de Sigmund Freud: Vol. XXI. Rio de Janeiro, RJ: Imago. (Original publicado em 1930)

Freud, S. (2006b). Três ensaios sobre a teoria da sexualidade. In S. Freud (Ed.), Edição standard brasileira das obras psicológicas completas de Sigmund Freud: Vol. VII. Rio de Janeiro, RJ: Imago. (Original publicado em 1905)

Goldenberg, M. (2005). Gênero e corpo na cultura brasileira. Revista Psicologia Clínica, 17(2), 6580. doi:10.1590/S0103-56652005000200006

Hernández, J. C. (2005). Patrimônio e globalização: $\mathrm{O}$ caso das culturas alimentares. In A. M. Canesqui \& R. W. D. Garcia (Eds.), Antropologia e Nutrição: Um diálogo possível (pp. 129-145). 
Rio de Janeiro, RJ: Editora Fundação Oswaldo Cruz. doi:10.7476/9788575413876

Jerusalinsky, J. (2006). Enquanto o futuro não vem. Salvador, BA: Ágalma.

Kakeshita, I. S., \& Almeida, S. S. (2006). Relação entre índice de massa corporal e a percepção da auto-imagem em universitários. Revista de Saúde Pública, 40(3), 497-504. doi:10.1590/S003489102006000300019

Lacan, J. (1998). O estádio do espelho como formador da função do eu. In J. Lacan, Escritos. Rio de Janeiro, RJ: Jorge Zahar. (Original publicado em 1949)

Leal, V. C. L. M., Catrib, A. M. F., Amorim, R. F., \& Montagner, M. A. (2010). O corpo, a cirurgia estética e a Saúde Coletiva: Um estudo de caso. Ciência \& Saúde Coletiva, 15(1), 77-86. doi:10.1590/S1413-81232010000100013

Lima, A. F., Batista, K. A., \& Lara, N., Jr. (2013). A ideologia do corpo feminino perfeito: Questões com o real. Psicologia em Estudo, 18(1), 49-59. doi:10.1590/S1413-73722013000100006

Marins, B. R., Araújo, I. S., \& Jacob, S. C. (2011). A propaganda de alimentos: Orientação, ou apenas estímulo ao consumo?. Ciência \& Saúde Coletiva, 16(9), 3873-3882. doi:10.1590/S141381232011001000023

Martins, C. R., Gordia, A. P., Silva, D. A. S., Quadros, T. M. B., Ferrari, E. P., Teixeira, D. M., \& Petroski, E. L. (2012). Insatisfação com a imagem corporal e fatores associados em universitários. Estudos de Psicologia (Natal), 17(2), 241246. doi:10.1590/S1413-294X2012000200007

Martins, C. R., Pelegrini, A., Matheus, S. C., \& Petroski, E. L. (2010). Insatisfação com a imagem corporal e relação com estado nutricional, adiposidade corporal e sintomas de anorexia e bulimia em adolescentes. Revista de Psiquiatria do Rio Grande do Sul, 32(1), 19-23. doi:10.1590/ S0101-81082010000100004

Mazzini, I. (2000). A alimentação e a medicina no mundo antigo. In J. L. Flandrin \& J. McDougall, Teatros do corpo. São Paulo, SP: Martins Fontes.

Ministério da Saúde. (2006). Obesidade. Cadernos de Atenção Básica, 12 - Série A. Normais e Manuais Técnicos.
Novaes, J. V., \& Vilhena, J. (2003). De Cinderela a moura torta: Sobre a relação mulher, beleza e feiura. Interações. 8(15), 9-36. Recuperado em http:// pepsic.bvsalud.org/scielo.php?pid=S1413$-29072003000100002 \&$ script $=$ sci_arttext

Oliveira, D. C. (2008). Análise de conteúdo temático-categorial: Uma proposta de sistematização. Revista Enfermagem UERJ, 16(4), 569-76. Recuperado em http://www.facenf.uerj.br/v16n4/ v16n4a19.pdf

Posavac, H. D., Posavac, S. S., \& Weigel, R. G. (2010). Reducing the impact of media images on women at risk for body image disturbance: Three targeted interventions. Journal of Social and Clinical Psychology, 20(3), 324-340. doi:10.1521/jscp.20.3.324.22308

Rocha, L. J. L. F., Vilhena, J., \& Vilhena Novaes, J. (2009). Obesidade mórbida: Quando comer vai muito além do alimento. Psicologia em Revista (Belo Horizonte), 15(2), 77-96. doi:10.5752/ P.1678-9563.2009V15N2P77

Saueressig, M. R., \& Berleze, K. J. (2010). Análise de influências em dietas de emagrecimento. Psico, 41(2), 231-238. Recuperado em http://revistaseletronicas.pucrs.br/revistapsico/ojs/index.php/ revistapsico/article/view/5538/5319

Secchi, K., Camargo, B. V., \& Bertoldo, R. B. (2009). Percepção da imagem corporal e representações sociais do corpo. Psicologia: Teoria e Pesquisa, 25(2), 229-236. doi:10.1590/S010237722009000200011

Seixas, C. M. (2009). Comer, demandar e desejar: Considerações psicanalíticas sobre o corpo e o objeto na Obesidade (Dissertação de mestrado, Instituto de Medicina Social, Universidade do Estado do Rio de Janeiro, Rio de Janeiro, RJ, Brasil). Recuperado em http://psicologado.com/abordagens/psicanalise/o-peso-da-obesidade-o-excesso-de-peso-como-sintoma\#ixzz36M1mgaik

Sibilia, P. (2006). O corpo editado e a carne impura. In W. Garcia (Ed.), Corpo e subjetividade: Estudos contemporâneos (pp. 97-107). São Paulo, SP: Factash.

Silva, H. C., \& Rey, S. (2011). A beleza e a feminilidade: Um olhar psicanalítico. Psicologia: $\mathrm{Ci}$ ência e Profissão, 31(3), 554-567. doi:10.1590/ S1414-98932011000300009 
Sousa, M. S. F. (2007). A busca pela cirurgia plástica e estética: Um sintoma da sociedade contemporânea? (Tese de doutorado, Pontifícia Universidade Católica de São Paulo, SP, Brasil). Recuperado em http://www.dominiopublico. gov.br/pesquisa/DetalheObraForm.do?select action $=\&$ co_obra $=85798$

Stenzel, L. M. (2006). A influência da imagem corporal no desenvolvimento e manutenção dos transtornos alimentares. In M. A. Nunes, J. C. Appolinario, A. L. Galvão, \& W. Coutinho, Transtornos alimentares e obesidade (2. ed., pp. 73-81). Porto Alegre, RS: Artmed.

Turato, E. R. (2003). Tratado da metodologia da pesquisa clínico-qualitativa: Construção teórico-epistemológica, discussão comparada e aplicação nas áreas de saúde e humanas. Petrópolis, RJ: Vozes.

Varela, A. P. G. (2006). Você tem fome de quê? Psicologia: Ciência e Profissão, 26(1), 82-93. doi:10.1590/S1414-98932006000100008
Winnicott, D. W. (1967). O papel de espelho da mãe e da família no desenvolvimento infantil. In D. W. Winnicott, $O$ brincar \& a realidade. Rio de Janeiro, RJ: Imago.

Zorzan, F. S., \& Chagas, A. T. S. (2011). Espelho, espelho meu, existe alguém mais bela do que eu?: Uma reflexão sobre o valor do corpo na atualidade e a construção da subjetividade feminina. Barbaroi, 34, 161-187. Recuperado em http:// online.unisc.br/seer/index.php/barbaroi/article/ view/1557/1561
Recebido: 26/02/2015

$1^{a}$ revisão: $30 / 11 / 2015$

Aceite final: 21/02/2016 